\title{
Early follow-up results of arteriovenous fistulae created for hemodialysis
}

\author{
This article was published in the following Dove Press journal: \\ Vascular Health and Risk Management \\ 17 May 20II \\ Number of times this article has been viewed
}

\author{
Hikmet lyem \\ Çanakkale 18 Mart, Üniversitesi Tip \\ Fakültesi, Turkey
}

Background: The aim of this study was to evaluate the site, early results, and postoperative complications of arteriovenous fistula (AVF) creation procedures for hemodialysis in our clinic.

Methods: The hospital records of 384 patients who underwent 411 AVF creation procedures for hemodialysis by the same team at our clinic between February 2008 and January 2010 were included for retrospective analysis. All procedures were performed under local anesthesia with lidocaine. Vasospasm was treated by mechanical dilatation with a probe and topical papaverine.

Results: Of our 384 patients, $58.5 \%$ were male and $41.5 \%$ were female. Mean age was 46 (range 12-72) years. Of the 411 AVF procedures performed, $106(25.8 \%)$ were created at the anatomical snuffbox, $264(64.3 \%)$ were Brescia-Cimino procedures, and 41 (9.9\%) were antecubital, brachiocephalic, or brachiobasilic procedures. Twenty-three patients $(5.98 \%)$ were subjected to more than one surgical intervention due to early thrombosis or failure of AVF. Early patency was found in $94.0 \%$ of the AVF created. Twenty-three patients underwent more than one surgical intervention due to early AVF thrombosis or failure. Early AVF failure occurred more often in females $(60.8 \%)$ than in males $(39.2 \%)$. Complications were observed in a total of $11.4 \%$ patients.

Conclusion: Mechanical dilatation of the artery and vein, before starting the anastomosis, as well as the use of vasodilatory agents, could decrease early thrombosis of the fistula, and this method has very high early patency.

Keywords: end-stage renal failure, arteriovenous fistula, early patency, complications

\section{Introduction}

According to the US Renal Data System, the incidence of fistula in the US was $26.3 \%$ in 1998 and increased to $36.3 \%$ in 2003 . Fistula prevalence also increased from $33 \%$ in 2003 to $41 \%$ in $2005 .{ }^{1}$ Patients with end-stage renal failure need to receive hemodialysis through an effective arteriovenous fistula (AVF) until renal transplantation. Therefore, it is essential that the AVF has long-term patency. ${ }^{2}$ Quinton first used the external arteriovenous shunt in 1960, and Brescia-Cimino used the endogenous arteriovenous shunt in $1966 .{ }^{3,4}$ Vascular access that provides a minimum flow of $250 \mathrm{~mL} / \mathrm{dk}$ is required for hemodialysis. AVFs are created to meet this requirement. For AVF creation, the veins of the patient need to be well preserved and not used previously. ${ }^{5,6}$ In patients with appropriate venous anatomy, all three types of AVF created on the upper extremity can supply adequate blood flow for hemodialysis. ${ }^{7}$ The radiocephalic Brescia-Cimino fistula created on the wrist is still the preferred AVF, although recently many surgeons ience: Hikmet lyem Çanakkale 18 Mart Üniversitesi Tip Fakültesi, Kalp Damar Cerrahisi AD, Çanakkale 17000, Turkey

Tel +902862180018

Fax +902862480393

Email hikmetiyem@gmail.com 
have been choosing to use the snuffbox AVF.,7-10 However, the possibility of inadequate AVF patency remains a problem. ${ }^{11,12}$ The purpose of this study was to evaluate the site, early results, and postoperative complications of AVFs created for hemodialysis in our clinic.

\section{Materials and methods}

The hospital records of 384 patients who underwent 411 AVF procedures for hemodialysis by the same team at our clinic between February 2008 and January 2010 were included in this retrospective analysis. All patients were physically evaluated, and the nondominant upper extremity was primarily chosen for AVF (ie, the left hand for right-handed patients and the right hand for left-handed patients). At the physical evaluation, arterial pulse strength, presence of a recent access, formation of a prominent elastic structure upon application of pressure, and vein diameters were assessed to determine the surgical site. For those patients who had more than one suitable site, the most distal one was generally selected in order to preserve the proximal site. Thrombosis formation within the first month was deemed "early". Fistulae that were developed two or more times were considered to be "repetition". All of the patients were followed up for the period starting from the creation of the AVF to the first hemodialysis.

\section{Surgical technique}

Because the intention was to preserve the opportunity to move the AVF more proximally, the AVF was created on the nondominant arm as distally as possible. All surgical operations were performed under local anesthesia using lidocaine hydrochloride (Jetmonal ${ }^{\circledR}$, Adeka, Istanbul, Turkey). When creating the fistula, factors such as prominence of superficial veins, history of thrombophlebitis, segmental stenosis in the proximal vessel, atherosclerosis of the radial artery, and blood flow were considered. Following exploration of the arteries and veins and prior to placing the clamp, heparin $(2 \mathrm{~mL})$ was routinely administered intravenously to each patient. If necessary, hemostasis was subsequently facilitated by neutralization of heparin using protamine sulfate. The end-to-side technique was preferred for distal anastomoses, and the side-to-side technique was preferred for proximal (antecubital) anastomoses. Vasospasm was treated by mechanical dilatation with a probe $(1 \mathrm{~mm}, 1.5 \mathrm{~mm}$, and $2 \mathrm{~mm}$ in diameter) and topical papaverine. For patients with inadequate venous flow, proximal dilatation was also performed using a Fogarty catheter. A continuous suture technique using 7/0 polypropylene was used to create the anastomoses.

\section{Statistical analysis}

SPSS Windows statistical software package (v 10.0; Chicago, IL) was used for data analysis. Continuous variables are presented as means \pm standard deviations. Student's $t$-test, Chi-square test, and Fisher's exact test were used. $P<0.05$ was accepted as being statistically significant.

\section{Results}

Of the 384 patients included in the study, 58.5\% were male and $41.5 \%$ were female. The mean age was 46 (range 12-72) years. Preoperative demographic data for the patients and causes of chronic renal failure are presented in Tables 1 and 2. Of 411 AVFs performed, 106 (25.8\%) received a snuffbox AVF, 264 (64.3\%) received a BresciaCimino AVF, and 41 (9.9\%) received an antecubital brachiocephalic, or brachiobasilic AVF (Table 3).

Early patency was found in $94.0 \%$ of the AVFs created. Most patients (320/384 [83.3\%]) were undergoing their first AVF formation, whereas 64 patients (16.7\%) had had at least one previous fistula. Surgical intervention was performed on the left upper extremity in 284 patients $(64.5 \%)$ and on the right upper extremity in 126 patients $(35.5 \%)$.

Seven patients $(6.6 \%)$ had early failure of a snuffbox AVF and $17(6.4 \%)$ had early failure of a Brescia-Cimino AVF. This difference was not statistically significant $(P>0.05)$. In total, 23 patients $(5.9 \%)$ were subjected to more than one surgical intervention due to early AVF thrombosis and failure. AVFs were created three times in eight patients and two times in 11 patients. Thrombectomy was utilized successfully in four patients who presented with early failure. There were no early failures in patients who underwent brachiocephalic or brachiobasilic AVF formation. Early AVF failure occurred more often in females (60.8\%) than in males $(39.2 \%, P<0.05)$.

Complications were observed in 44 patients (11.4\%). Specifically, early thrombosis was seen in 23 patients and complications of the surgical area occurred in 21 patients. Five patients had hyperemia at the incision site, four

Table I Patient demographics

\begin{tabular}{lll}
\hline Parameters & $\mathbf{n}$ & $\%$ \\
\hline Patients/fistulae created & $384 / 4 \mathrm{II}$ & \\
First AVF creation & 320 & 83.3 \\
Male & 225 & 58.5 \\
Female & 159 & 41.5 \\
Diabetes & 234 & 60.9 \\
Hypertension & 184 & 47.9 \\
\hline
\end{tabular}

Abbreviation: AVF, arteriovenous fistula. 
Table 2 Causes of chronic renal failure in dialyzed patients

\begin{tabular}{lll}
\hline Disease & $\mathbf{n}$ & $\%$ \\
\hline Polycystic renal disease & 37 & 9.63 \\
Nephroangiosclerosis & 25 & $6.5 \mathrm{I}$ \\
Glomerulonephritis & $\mathrm{III}$ & 28.9 \\
Chronic pyelonephritis & 57 & 14.84 \\
Diabetes & 29 & 7.55 \\
Hypertension & $\mathrm{II}$ & 2.86 \\
Renal amyloidosis (primary or secondary) & 4 & 1.04 \\
Urological disease (stones, obstruction) & 3 & 0.78 \\
Other & 25 & $6.5 \mathrm{I}$ \\
Unknown & 82 & 21.35 \\
\hline
\end{tabular}

had infection at the incision site, seven had hematoma at the incision site, five had revisions due to hemorrhage. Regression of hyperemia and infection was achieved by standard antibiotic therapy, and re-exploration was performed for hematoma. There were no early venous hypertension or vascular steal occurrences associated with brachiocephalic or brachiobasilic AVF formation (Table 3). The patients embarked on dialysis approximately $4.7 \pm 1.8$ weeks after the AVFs were created.

\section{Discussion}

In this study, we investigated the early patency rate for AVFs created in end-stage renal failure patients, factors affecting patency, and postoperative complications. AVFs are created internally or with grafts for hemodialysis, which is a treatment option for end-stage renal failure patients. Although there are many methods for creating an AVF, the most commonly preferred are the Brescia-Cimino and snuffbox methods. When distal access attempts fail for a variety reasons, repeat surgery can be undertaken to create new AVFs, and a brachiocephalic or brachiobasilic AVF can be created on the forearm.

Table 3 Types of AVF created and postoperative complications

\begin{tabular}{lll}
\hline AVF types & $\mathbf{n}$ & $\%$ \\
\hline Snuffbox & 106 & 25.8 \\
Brescia-Cimino & 264 & 64.3 \\
Brachiocephalic & 29 & 7.00 \\
Brachiobasilic & 12 & 2.91 \\
Complications & & \\
Early thrombosis & 23 & 5.98 \\
Hyperemia of incision site & 5 & 1.30 \\
Infection of incision site & 4 & 1.04 \\
Hematoma on incision site & 7 & 1.82 \\
Revision due to hemorrhage & 3 & 0.78 \\
Fistula not maturing & 2 & 0.52 \\
\hline
\end{tabular}

Abbreviation: AVF, arteriovenous fistula.
Because there are various reasons for failure, it is appropriate to examine AVF patency rates in two groups, ie, early failures and late failures. Reasons for early failure include use of ill-suited veins, severe dehydration, obstruction of the outlet, a poor anastomosis, a vein kink near the anastomosis, and compression of a hematoma. ${ }^{11,12}$ Reasons for late failure include stenosis of the anastomosis line during and after development of intimal hyperplasia, fibrous tissue development on the vein walls due to needle puncture trauma, and calcium phosphate deposition on the anastomosis line. ${ }^{13}$

A wide range of early failure rates have been reported in the literature. Da Silva et a $\mathbf{~}^{14}$ reported a $15 \%$ early failure rate, Baldrati et al $13.5 \%,{ }^{15}$ Sozudogru et al $18 \%,{ }^{16}$ and Ozköleli et al $18.8 \%{ }^{17}$ Early failure rates in the range of $12 \%-29 \%$ have been observed in other studies. ${ }^{6,18,19}$ In a study that evaluated 169 AVFs created in 122 patients, early patency was found to be $73.6 \%$ (early failure $26.4 \%$ ), which decreased to $64.6 \%$ in the long-term, emphasizing that the early period is important for fistula patency. ${ }^{20}$ Also, Ekici et al ${ }^{21}$ reported a $12 \%$ early thrombosis rate. Fitzgerald et $\mathrm{al}^{22}$ reported that $2 \%$ of early thrombosis occurred after first use of the AVF. This study found an early thrombosis rate (5.98\%) lower than that reported in the literature. This lower early thrombosis rate is attributed to the use of mechanical dilatation with a probe for spasm of both the arteries and veins, and to the use of topical papaverine. Hence, a proportion of early failure can be attributed to technical inadequacy, which can be avoided.

In a study by Miller et al, ${ }^{23}$ the success rate of AVFs on the forearm was reported to be lower in women than in men. Gibbons ${ }^{24}$ also reported lower patency rates in women. However, there are also studies that did not show a gender difference. Baser et al ${ }^{25}$ created 132 AVFs on 114 patients and did not find a gender difference in either early or late failure or in patency rates. Another study also found no difference in AVF patency rates between women and men. ${ }^{21}$ The present study was consistent with the presence of a gender difference, finding early failure rates of $60.8 \%$ for women and of $39.2 \%$ for men.

In the early period following AVF formation, there may be a need for hospitalization or surgical revision due to local complications, such as thrombosis, hematoma, hemorrhage, or infection. ${ }^{26-29}$ The most common complication, early and late, is thrombosis of the fistula $(3.0 \%-14.5 \%){ }^{28,30}$ In the present study, complications other than early thrombosis, such as revisions due to hyperemia, hematoma, infection, and hemorrhage at the incision site, were also occasionally observed. Although Horimi et a ${ }^{31}$ reported that AVF patency rates were significantly lower for diabetic patients, both 
Wolowczyk et $\mathrm{al}^{30}$ and Ekici et $\mathrm{al}^{21}$ found that diabetes had no effect on AVF patency rates. Field et $\mathrm{al}^{32}$ reported that fistula survival rates in nondiabetic patients were higher than in patients with diabetes, but this difference was not significant. However, Erkut et $\mathrm{al}^{33}$ also reported that diabetes mellitus was one of the factors affecting the primary patency of AVF. No relationship was found between diabetes and fistula patency rate in this study.

Given that only $11 \%$ of end-stage renal failure patients undergo renal transplantation, ${ }^{34}$ and that the rest need regular and effective hemodialysis to maintain their lives at a certain level of quality, maximum care should be taken during the preoperative evaluation of the AVF created, as well as with the surgical technique.

\section{Conclusion}

In this study, the early fistula patency rate was better that in prior reports, and there are two possible explanations for this. Firstly, preoperative evaluation of the patients was performed very carefully, enabling the most appropriate site for AVF to be determined. Secondly, careful consideration was given to the anastomosis technique, which included mechanical dilatation and a vasodilatory agent for both the artery and vein in each patient. Mechanical dilatation of the artery and vein, before starting the anastomosis, as well as the use of a vasodilatory agent can decrease the risk of early thrombosis of the fistula. Although the high patency rate of the AVFs in this study may be due to this intervention, further randomized studies comparing mechanical dilatation and papaverine with mechanical dilatation and/or placebo are warranted to define the exact role of these interventions.

\section{Disclosure}

The author reports no conflicts of interest in this work.

\section{References}

1. Pflederer TA, Kwok S, Ketel BL, Pilgram T. A comparison of transposed brachiobasilic fistulae with nontransposed fistulae and grafts in the Fistula First era. Semin Dial. 2008;21:357-363.

2. Dilege S, Baktıroglu S, BașarY, Genc FA, Ozgur F. Basilic vein transposition as vascular access for hemodialysis. Turkish J Thorac Cardiovasc. 1995;3:140-142.

3. Quinton WE, Dillard D, Scribner BH. Cannulation of blood vessels for prolonged hemodialysis. Tr Amer Soc Artif lnt Organs. 1960;6:104.

4. Brescia MJ, Cimino JE. Chronic hemodialysis using vein puncture and a surgically created artiriovenous fistula. $N$ Engl J Med. 1966;275: 1089-1094.

5. Wada H, Ierardi RP, Coll D, Matsumoto T. Immediate postoperative complications following hemodialysis access procedures. Int Surg. 1996;81:99-101.

6. Fernström A, Hylander B, Olofsson P, Swedenborg J. Long and short term patency of radiocephalic arterıovenous fistulas. Acta Chir Scand. $1988 ; 154: 257-259$.
7. Fitzgerald JT, Schanzer A, Chin AI, McVicar JP, Perez RV, Troppmann C. Outcomes of upper arm arteriovenous fistulas for maintenance hemodialysis access. Arch Surg. 2004;139:201-208.

8. Bonalumi U, Civalleri D, Doyvida S, et al. Nine years experience with end to end arteriovenous fistula at the anatomical snuff box for maintenance hemodialysis. Br J Surg. 1982;69:486-488.

9. Haberal M, Gülay H, Kaynaroğlu V, et al. Snuff box vascular access for hemodialysis. Dial Transpl Burn J. 1983;1:363-367.

10. Keceligil HT, Kolbakır F, Arıkan A, Canbaz S. Postoperative complications following hemodialysis access procedures. J Exp Clin Med. 1998; 15:301-305.

11. Haimovici H, Steinman C, Caplan L. Role of arteriovenous anostomoses in vascular diseases of the lower extremity. Ann Surg. 1966;164: 990

12. Mandel SR, Martin PL, Blumoff RL, Mattern WD. Vascular access in a university transplant and dialysis program. Result, costs and manpower implications. Ann Surg. 1977;112:1375.

13. Olsson LF, Odselius R, Ribbe E, Hegbrant J. Evidence of calcium phosphate depositions in stenotic arteriovenous fistulas. Am J Kidney Dis. 2001;38:377-383.

14. Da Silva AF, Escofet X, Rutherford PA. Medical adjuvant treatment to increase patency of arterionenous fistulae and grafts. Cochrane Database Syst Rev. 2003;CD002786.

15. Baldrati L, De Pascalis A, Giudicissi A, Docci D, Neri L, Feletti C. Pre-dialysis arteriovenous fistula results in better patency rate. G Ital Nefrol. 2003;20:166-169. [Italian].

16. Sozudogru AN, Cangel U, Eryuksel B, Besirli K, Kavak MK, Coskun H. Early and late results of the arteriovenous fistulae created for hemodialysis: A retrospective clinical study. Turkish $J$ Thorac Cardiovasc. 1999;7:135-139.

17. Ozköleli M, Koseoglu B, Ekim H, Erkoc H, Sonmez B. Retrospective analysis of arteriovenous fistulas for hemodialysis in our hospital within last one year. J Van Med. 2000;7:113-116.

18. Nazzal MMS, Neglen P, Naseem J, Christenson JT, Al-Hassan HKH. The brachiocephalic fistula: A successful secondary vascular access procedure. Vasa. 1990;19:326-329.

19. Kherlakian GM, Roedersheimer LR, Arbaugh JJ, Newmark KJ, King LR. Comparison of autogenous fistula versus expanded polytetrafluoroethylene graft fistula for angioaccess in hemodialysis. Am J Surg. 1986;152:238-243.

20. Doğu N, Duran E, Karagöz H, et al. Chronic arterio-venous fistulas in hemodialysis patients. İstanbul Tabip Odast-Klinik Gelişim Dergisi. 1992;5(2)

21. Ekicei Y, Karayalı FY, Yagmurdur FC, et al. Snuff-box arteriovenous fistula for hemodialysis. Turkish Vasc Surg. 2008;17:73-79.

22. Fitzgerald JT, Schanzer A, Chin AI, McVicar JP, Perez RV, Troppmann C. Outcomes of upper arm arteriovenous fistulas for maintenance hemodialysis access. Arch Surg. 2004;139:201-208.

23. Miller PE, Tolwani A, Luscy CP, et al. Predictors of adequacy of arteriovenous fistulas in hemodialysis patients. Kidney Int. 1999;56: 275-280.

24. Gibbons CP. Primary vascular access. Eur J Vasc Endovasc Surg. 2006;31:523-529.

25. Baser M, Sayarlioglu H, Dogan E, Erkoc R, Cifci A, Kotan MC. Comparison of proximal distal success rate in A-V fistulas settled for hemodialysis. J Van Med. 2006;13:42-45.

26. Konner K, Hulbert-Shearon TE, Roys EC, Port FK. Tailoring the initial vascular access for dialysis patients. Kidney Int. 2002;62: 329-338.

27. Utzig MJ, Foitzik TH, Dollinger P, Buhr HJ. Patency of surgically revised ePTFE-dialysis access grafts. Zentralbl Chir. 2002;127: 123-127. [German]

28. Meyer F, Müller JS, Bürger T, Halloul Z, Lippert H. Experiences with ambulatory arteriovenous shunt surgery. A cost-benefit analysis. Chirurg. 2002;73:274-278. [German].

29. Dikow R, Schwenger V, Zeier M, Ritz E. Do AV fistulas contribute to cardiac mortality in hemodialysis patients? Semin Dial. 2002;15:14-17. 
30. Wolowczyk L, Williams AJ, Donovan KL, Gibbons CP. The snuffbox arteriovenous fistula for vascular access. Eur J Vasc Endovasc Surg. 2000;19:70-76.

31. Horimi H, Kusano E, Hasegawa T, Fuse K, Asano Y. Clinical experience with an anatomic snuff box arteriovenous fistula in hemodialysis patients. ASAIO J. 1996;42:177-180.

32. Field M, MacNamara K, Bailey G, Jaipersad A, Morgan RH, Phervwani AD. Primary patency rates of AV fistulas and the effect of patient variables. J Vasc Access. 2008;9:45-50.
33. Erkut B, Unlü Y, Ceviz M, et al. Primary arteriovenous fistulas in the forearm for hemodialysis: Effect of miscellaneous factors in fistula patency. Ren Fail. 2006;28:275-281.

34. Turkish Society of Nephrology. Registry of the Nephrology, Dialysis and Transplantation in Turkey. Registry 2004. Omega CRO. Istanbul, Turkey: Turkish Society of Nephrology; 2005. Available at: http://www. tsn.org.tr/folders/file/Registry_2006_Eng_tr.pdf. Accessed April 10, 2011.

\section{Publish your work in this journal}

Vascular Health and Risk Management is an international, peerreviewed journal of therapeutics and risk management, focusing on concise rapid reporting of clinical studies on the processes involved in the maintenance of vascular health; the monitoring, prevention and treatment of vascular disease and its sequelae; and the involvement of metabolic disorders, particularly diabetes. This journal is indexed on PubMed Central and MedLine. The manuscript management system is completely online and includes a very quick and fair peer-review system, which is all easy to use. Visit http://www.dovepress.com/ testimonials.php to read real quotes from published authors.

Submit your manuscript here: http://www.dovepress.com/vascular-health-and-risk-management-journal 